Pinilla-Portiño, 2018

Volume 3 Issue 3, pp.1673-1682

Date of Publication: 20 th February 2018

DOI-https://dx.doi.org/10.20319/pijss.2018.33.16731682

This paper can be cited as: Pinilla-Portiño , N. (2018). Language Policy Planning As a Political Tool for Social Stratification: Analysing the Case of Paraguay. PEOPLE: International Journal of Social Sciences, 3(3), 1594-1603.

This work is licensed under the Creative Commons Attribution-Non-commercial 4.0 International License. To view a copy of this license, visit http://creativecommons.org/licenses/by-nc/4.0/ or send a letter to Creative Commons, PO Box 1866, Mountain View, CA 94042, USA.

\title{
LANGUAGE POLICY PLANNING AS A POLITICAL TOOL FOR SOCIAL STRATIFICATION: ANALYSING THE CASE OF PARAGUAY
}

Nykoll Pinilla-Portiño

School of Languages \& Cultures, The University of Queensland, Brisbane, Australia nykollpinilla@gmail.com

\begin{abstract}
In the study of unequal societies as the result of language use, the Paraguayan case stands out among several realities. Paraguay is a South American country which offers a unique opportunity to analyse how language(s) may influence the socioeconomic position or social mobility of people. In this scenario, the present article analyses the political purposes that Language Policy and Planning (LPP) has served in Paraguay as well as the consequences this approach has produced regarding society segmentation.

Through a literature review, the text emphasises how LPP was developed in an early and modern stage of the Paraguay government. On this regard, a dangerous relationship between the government's political wing and the approach of LPP is exposed. Moreover, society stratification is understood as one of the main consequences of this link. Finally, a reflection about possible considerations when designing LPP is proposed in the conclusion.
\end{abstract}

\section{Keywords}




\section{Introduction}

Language Policy and Planning (LPP) is a process that involves several decisions regarding language use (Hamid \& Nguyen, 2016). These decisions directly influence people's linguistic choices. Furthermore, LPP decisions may also impact aspects related to people's identity such as their socioeconomic profile, position and their possibilities for social mobility (Hamid, 2016).

The present article is a literature revision which aims to analyse LPP in Paraguay as the motor for social stratification. During this analysis, political interests are conceived as the main catalysts for society segmentation in Paraguay. To accomplish this objective first, the concept of LPP will be defined to provide a clear view of its relationship with politics. Second, the early and modern state of macro-level LPP in Paraguay will be analysed regarding the political speech and practice behind them. Third, the effects generated by the relationship between LLP and politics in Paraguayan society structure will be addressed. Finally, main ideas from this analysis will be discussed in the conclusion.

\section{The Concept of LPP}

In very broad terms, the concept of LPP refers to the decisions made about the use of language in a context. Thus, LPP framework is closely related to politics (Hamid \& Baldauf, 2014). However, to have a clear view about how LPP relates to politics as well as how this relationship may impact society, it is necessary to review how different perspectives have modelled and conceptualised LLP design through history.

During a first stage, LPP was understood from a formal-institutional perspective. Rubin and Jernudd (1971), described it as a deliberate and purposeful change in individuals' language code or the way of speaking, which was planned and established by an organization. Likewise, Kaplan and Baldauf (1997), conceived LPP as the set of regulations and laws established by an authority figure to produce a linguistic change in a society. Furthermore, Tollefson (1991), sustained that LPP, as the institutionalisation of language, was a production of dominant social groups for society structuration. 
The previous approach to LPP could be summarised as the macro-level language policies which are designed by the political institutions in government and implemented in society with a top-down direction through a state official educational system (Bartlett, 2017).

In a later stage, LPP concept was strongly influenced by the sociocultural approach. Schiffman (1996) refused to framed LLP concept as the establishment of explicit rules for language use. Instead, the author claimed that LPP was also a social construction of implicit practices in a polity, such as the speakers' culture, beliefs and attitudes. Likewise, McCarty (2011), characterised LPP concept from the human-interaction point of view. In other words, these two authors grounded LPP concept to individuals' daily language use, which is mediated by relations of power and massified throughout official or unofficial media (Sinaga, 2015).

This approach to LPP may be seen as contrary to the early stage of LPP conceptualisation as it also considers LPP as micro-level language policies which may be unconsciously design by the speakers themselves and implemented in a multilateral or bottom-up direction.

Currently, the area of LPP has been addressed as a framework, which consist of the following planned steps (Hamid, 2016; Kaplan \& Baldauf, 1997; Ricento, 2006):

- The status planning, which is the selection of an official language for a state.

- $\quad$ The corpus planning, which relates to the linguistic goals to achieve.

- The cultivation planning, which refers to the enhancing of linguistic functions or forms.

- $\quad$ The acquisition planning, which lies on how the language will be learned.

- $\quad$ The prestige planning, which is the image or vision of the language

Although the detailed framework provides a clear vision of the steps to be taken for the development of LPP, it does not provide orientations of who the responsible of these decisions may be and the which criteria they should follow when making these decisions. As a result, the design of LPP is always undefined and ambiguous.

As the present essay analyses LPP in Paraguay as a mechanism to structure society, the concept of LPP will be approached from a formal-institutional perspective. Therefore, LPP framework will be understood as the language hegemony established by authority figures as dominant social groups that are in the position to modify society linguistics choices (Kaplan \& Baldauf, 1997; Rubin \& Jernudd, 1971). Consequently, individuals' language use is inevitable perceived as an instrument of power within society that directly influences their social class and mobility (Tollefson, 1991). 


\section{Methodology}

This article aims at analysing LPP in Paraguay by stressing the role of political interests regarding the stratification of Paraguayan society. To accomplish this objective, literature regarding the approaches of LPP according to different political wings was reviewed and analysed in terms of the following questions:

- $\quad R Q$ 1: Which is the relationship between LPP and politics in Paraguay?

- RQ2: How can LPP, as a political speech and practice, influence society structuration in Paraguay?

\section{Which is the Relationship between LLP and Politics in Paraguay?}

The relationship between LPP and politics in Paraguay has its roots in distant past. According to Gynan (2001), it was during the Spanish invasion, followed by the colonisation period that this connection got strengthened. To illustrate this, the same author referred to the theory of Linguistic Imperialism, which described the process of how the settlers imposed their linguistics resources over local linguistics ecology (aboriginal languages) from the colonised areas (Canagarajah, 1999). In this case the imposition of Spanish over Guaraní, the language used in the region that it is now known as the Republic of Paraguay (Gynan, 2001). Consequently, a language hierarchy emerged. In this hierarchisation, the native languages were subjugated to settlers' languages through the establishment of a new political hegemony.

The described process affected the native communities at a variety of levels, but particularly in terms of social structure. The imposition of an unknown language, a "sophisticated culture" and the "rightful religion", left the natives' languages, beliefs and customs relegated to a second place, as second-order citizens of the new construction of society. As an immediate consequence, the new social arrangement caused feelings of resistance among the native population, who continued speaking Guaraní language in reaction to settlers' enactment of power. This sociocultural imposition generated relevant consequences in current Paraguay's social stratification. Particularly, the suppression of local cosmovision provoked the economic and educational impoverishment of aboriginal population as their culture was not considered in the new social schemata. 
At present, LPP usually takes place in a more democratic context. According to Liu and Ricks (2012), modern LPP is not a static establishment instead, it is a dynamic framework that may shift and shape over time regarding the coalitional composition of governments during state development. Nevertheless, LPP decisions are still made by dominant groups in society, which are in a position of power when compared to the rest of the state citizens. Thus, LLP continued being a sensitive issue as it is still a field of power enactment despite the setting of a democratic state system. Therefore, dominant groups' ideologies, normative assumptions and language use are inevitably embedded in LPP (Barakos \& W. Unger, 2016).

The previous characterisation of LPP resembles the reality of Paraguay since LPP has been the main concern for the government disregarding its political party tendency. However, drastic differences have been noted in how different governments have approached LPP framework in Paraguay. Then, it is not surprising to think that these differences may lay on political interests related to distinct political wings.

On regard of the consequences that the connection between LPP and politics may have for society, these can be categorised as material or symbolic effects as well as an overlapping of these two. On the one hand, the material effects refer to the stratification of society regarding power (Barakos \& W. Unger, 2016). For instance, an educated social class, which is rich and powerful versus an uneducated social class, which is poor and weak. In this dichotomy, language development and proficiency are used as the criteria for group division. On the other hand, the symbolic effects relate to individuals' identity and language. For example, decisions about the corpus planning and the cultivation planning of LPP (Barakos \& W. Unger, 2016).

To illustrate the previous point in the Paraguayan context, the beginning of LPP framework in Paraguay must be referred. The very first formal rule about language use in early Paraguay came from Spanish settlers. However, as the aboriginal population reacted negatively to Spanish as the official language, and as the presence of Spanish colonies was still weak in the region, the Guaraní native language continued being the main language regardless Spanish officialization. As a result, Spanish colonies were constituted in central bases, where Spanish was spoken, while native population set in rural peripheral areas, where Guaraní was the main language (Gynan, 2001). Thus, linguistic division accompanied of a geographical location led to differences in society structuration, which are still present in the modern Republic of Paraguay. Consequently, educated monolingual Spanish speakers lived and still living, in the urban-central 
areas, whereas uneducated native monolingual Guaraní speakers lived and are living as farmers in poor rural areas (Mortimer, 2013; Porter, 1990).

The described situation exemplifies how an early and an unpolished approach to language use decisions gave birth to a social structure, which despite the advances and improvement of modern LPP framework in Paraguay, remains the same. Therefore, it could be argued that there were political interests behind LPP framework during the decolonisation period, and there still are political intentions that underline current LPP scheme in Paraguay.

\section{How can LPP, as a Political Speech and Practice, Influence Society Structuration in Paraguay?}

Throughout Paraguayan history, drastic changes in LPP framework have been noted. These changes are curiously enacted by different governments from opposed political wings. To illustrate this, two emblematic cases will be exposed.

First, after the decolonisation process around 1880, the General Bernardino Caballero from the national liberal party reached the powered and declared himself president of the Republic of Paraguay (Gynan, 2001). During his governments, that lasted six years, he developed severe and restrictive language policies that banned the use of Guaraní language. Consequently, a Spanish speaking elite emerged. The members of this elite were educated citizens, who supported Caballeros' dictatorship. Thus, they enjoyed a powerful social position. Furthermore, members of this elite also participated as politicians in the regimen (Barakos \& W. Unger, 2016).

The addressed antecedent of LPP framework, was lately understood as a tool to segregate Paraguayan society since the privileged position of the dominant social group was ensured, while Guaraní speakers were isolated in marginal social contexts. In this situation, LPP was used as a strategy to legitimate a hegemony and lead to social inequality and injustice. As stated by Liu and Ricks (2012), the linguistic group that have access to government power include their political purposes to determine LPP in a state.

Second, around 1950 Caballero's prohibition of Guaraní language changed when Alfredo Stroessner, a populist politician from the state party, was democratically elected president of the Republic of Paraguay (Gynan, 2001). During his period, Stroessner foster Guaraní speakers' leaders to fight back the Spanish dominant elite to promote the growing of agriculture to 
strengthen national economy. Although Stroessner LPP framework fostered the functionality of Guaraní language, the social structure remained the same; uneducated Guaraní speakers’ farmers located in peripheral rural areas and educated Spanish speakers living in the city (Barakos \& W. Unger, 2016). In addition, if we consider the fact that Stroessner established another dictatorship after his presidential period that lasted 35 years, the unchanged social stratification inevitably became a suspicious issue.

Currently, Paraguay has approached LPP framework in a more consensual setting, where Guaraní and Spanish were both share the official language status of the Republic. In this context, the educational reform of 1992, which addressed substantial improvements regarding LPP, was developed (Gynan, 2001). Among these improvements there was the implementation of the national Spanish-Guaraní bilingual program in primary and secondary schools. The bilingual program was created as part of the acquisition planning to foster the equal learning of the two languages. In addition, the program aimed to be equivalent; that is to say, a Spanish speaking student had the right to be educated in Spanish, as well as to be instructed in Guaraní and vice versa in the case of Guaraní speaking students. The bilingual education program also promoted parents' literacy in both languages to reinforce networks of language support for the students. However, after 26 years of its implementation, the bilingual program did not produced the expected changes in education, nor in society structuration (Ito, 2012). Some of the issues that deprived the successful implementation of the bilingual program was the emphasis the government devotes to Spanish literacy and the restrictive role of Guaraní as official language (Ito, 2012). This can be reflected in the following aspects (Gynan, 2001):

- Paraguay government employs Spanish only for official oral or written communication.

- Spanish is the main source for media production.

- The development of knowledge by the academia is conducted in Spanish.

- University education is carried out in Spanish.

Regarding the previous points, it could be argued that there may be a double discourse, as well as political purposes behind the declaration of Guaraní as an official language. On the one hand, a double discourse because it seems that the status of official language is a just a label, rather than a real functionality for Guaraní since Spanish is still the dominant and prestigious language in practice (Gynan, 2001). On the other hand, there are political purposes involved in current LPP framework because although the previous point, the government continued fostering 
the bilingual equivalent program to literate people in Guaraní, a language no longer used in formal and higher education settings. Thus, linguistic inequality continued growing in Paraguay (Porter, 1990).

The addressed landscape has influenced the prestige planning of Spanish and Guaraní, since opposed images between these two languages have been generated; being Guaraní the socially inferior language, whereas Spanish is the socially accepted and valued language. At the present, Spanish and Guaraní are widely spoken among Paraguayan population, with rates of $87 \%$ and 95\% respectively. However, according to Gynan (2001), there is still a 52\% of the habitants that are Guaraní monolinguals, who continued being the poor and uneducated people. Whereas, Spanish is still the language of urban social and economic advantaged areas.

\section{Conclusion}

The present article attempted to characterise LPP as the motor for society stratification in Paraguay. To achieve this objective, the concept of LPP was defined from a formal-institutional perspective. Thus, LPP was conceived as a language hegemony, which is designed and established by an authority figure (Rubin \& Jernudd, 1971). During this process, the authority figure's ideologies and values are inevitably embedded in LPP. Thus, LPP framework can affect and shape society structuration (Kaplan \& Baldauf, 1997). As a result, subjects' development of language is a tool of power that can define their social class and position (Tollefson, 1991).

During the essay development, different LPP approaches from opposed political wings implemented in Paraguay were reviewed to illustrate how distinct LPP can be regarding the government political tendency. Throughout this review, the noticed differences were assumed to be political interests behind LPP frameworks. As result of these drastic differences among three distinct LPP implementation, effects on society structuration were found. These effects referred to the extrapolation of two social groups that had led to opposed images of the two official languages in Paraguay. On the one side, the Guaraní monolinguals as the uneducated, poor and rural social class. On the other side, the Spanish monolinguals as the educated, advantaged and urban social class.

Finally, it could be said that LPP is a field of complex choices since it involves making decisions about individuals' language use. Therefore, it will never be a neutral resolution. As so, the scope of the possible effects of LPP framework will always be undermined. Furthermore, 
LPP will always be developed and situated in a context. Thus, concepts such as history, individuals' identity, citizenship, nation and culture are inherent to LPP framework (Hult \& Johnson, 2015).

\section{References}

Barakos, E., \& W. Unger, J. (2016). Discursive Approaches to Language Policy edited by Elisabeth Barakos, Johann W. Unger. London, UK: Palgrave Macmillan. https://doi.org/10.1057/978-1-137-53134-6

Bartlett, K. A. (2017). The divide between policy and practice in EFL high school classrooms in Japan. PEOPLE: International Journal of Social Sciences, 3(3), 198-

217. https://doi.org/10.20319/pijss.2017.32.198217

Canagarajah, S. (1999). Resisting linguistic imperialism in English teaching. Oxford: Oxford University Press.

Gynan, S. N. (2001). Language Planning and Policy in Paraguay. Current Issues in Language Planning, 2(1), 53-118. https://doi.org/10.1080/14664200108668019

Hamid, M. O. (2016). The politics of language in education in a global polity. In A. G. K. Mundy, B. Lingard, \& A. Verger (Ed.), The handbook of global education policy (pp. 259-274). London: Wiley Blackwell. https://doi.org/10.1002/9781118468005.ch14

Hamid, M. O., \& Baldauf, R. B., Jr. (2014). Public-Private Domain Distinction as an Aspect of LPP Frameworks: A Case Study of Bangladesh. Language Problems and Language Planning, 38(2), 192-210. https://doi.org/10.1075/1plp.38.2.05ham

Hamid, M. O., \& Nguyen, H. T. M. (2016). Globalization, English language policy, and teacher agency: Focus on Asia. International Education Journal: Comparative Perspectives, 15(1), 26-44.

Hult, F. M., \& Johnson, D. C. (2015). Research Methods in Language Policy and Planning A Practical Guide. Hoboken: Wiley.

Ito, H. (2012). With Spanish, Guaraní lives: a sociolinguistic analysis of bilingual education in Paraguay. Multilingual Education, 2(1), 1-11. https://doi.org/10.1186/2191-5059-2-6

Kaplan, R. B., \& Baldauf, R. B. (1997). Language planning from practice to theory / Robert B. Kaplan, Richard B. Baldauf. Clevedon, [Eng.] Philadelphia: Multilingual Matters.

Liu, A. H., \& Ricks, J. I. (2012). Coalitions and Language Politics: Policy Shifts in Southeast Asia. World Pol., 64(3), 476-506. https://doi.org/10.1017/S004388711200010X 
McCarty, T. L. (2011). Ethnography and language policy. London: Springer.

Mortimer, K. S. (2013). Communicative event chains in an ethnography of Paraguayan language policy. International Journal of the Sociology of Language, 2013(219), 67-99. https://doi.org/10.1515/ijsl-2013-0005

Porter, R. P. (1990). Forked tongue : the politics of bilingual education / Rosalie Pedalino Porter. New York: Basic Books.

Ricento, T. (2006). An introduction to language policy: theory and method / edited by Thomas Ricento. Malden, MA: Blackwell Pub. https://doi.org/10.1007/s10993-005-3200-X

Rubin, J., \& Jernudd, B. H. (1971). Can language be planned? : Sociolinguistic theory and practice for developing nations / edited by Joan Rubin and Bjorn H. Jernudd. Honolulu: Honolulu : University Press of Hawaii.

Schiffman, H. (1996). Linguistic Culture and Language Policy. London: Taylor and Francis. https://doi.org/10.4324/9780203273487

Sinaga, M. (2015). Ktpuntukahok: The role of social media as a tool of social movement. PEOPLE: International Journal of Social Sciences, 1(1), 369-374.

Tollefson, J. W. (1991). Planning language, planning inequality / James W. Tollefson. London, New York: Longman. 